\title{
Analysis of Chicken T Cell-Mediated Responses on Thymus after Immune Stress
}

\author{
Zhenhu Jia, Yufang Cao, Yaju Xue, Fangxiang Li, Min Liu, Cai Zhang, Yufei Yang, \\ Jiangyan Duan* \\ College of Life Science, Shanxi Normal University, Linfen, China \\ Email: ‘ianyanduan@163.com
}

Received 5 March 2014; revised 4 April 2014; accepted 11 April 2014

Copyright (C) 2014 by authors and Scientific Research Publishing Inc.

This work is licensed under the Creative Commons Attribution International License (CC BY). http://creativecommons.org/licenses/by/4.0/

(c) (i) Open Access

\begin{abstract}
In order to assess chicken $T$ cell-mediated responses after immune stress, 200 two-week-old chickens were randomly divided into control group(C) and treatment groups $\left(T_{1}\right.$ and $\left.T_{2}\right)$. The live I-type of Newcastle disease vaccine (ND) was taken as the source of immunological stress. The chickens in group $\left(T_{2}\right)$ were injected with overdose of live I-type Newcastle disease vaccine. After vaccination, the dynamic changes of $\mathrm{CD4}^{+}, \mathrm{CD8}^{+} \mathrm{T}$ cells on thymus were detected by immunohistochemistry. The ultra-structure of $T$ cells on thymus of the chickens in group $\left(T_{2}\right)$ was observed by electron microscopic. The result showed: (1) After immune stress, from day 1 to day 5 , the number of the CD4+T cells significantly declined and reached the bottom at day 5 , but the number of the CD8+T cells increased dramatically and peaked at day 5. (2) After immune stress, from day 1 to day 5, part of $T$ cells of chicken thymus came with apoptotic and pathological changes of putrescence continually. These results underscore: the immune stress can cause transient immune adjustment. These changes for chickens were the self-protection mechanism of immune system to adapt to survival and avoid immune disorder.
\end{abstract}

\section{Keywords}

T Cells, Chicken Thymus, Immunological Stress

\section{Introduction}

Vaccines, which could induce protective immunity while producing a minimal antagonistic response in the bird, play an increasing role in disease control of poultry [1]. To strengthen the immunity of chicken to decrease economic losses at harvest, nowadays, poultry producer tends to overdose on vaccines. However, it may trigger

\footnotetext{
${ }^{*}$ Corresponding author.
}

How to cite this paper: Jia, Z.H., et al. (2014) Analysis of Chicken T Cell-Mediated Responses on Thymus after Immune Stress. Journal of Immune Based Therapies, Vaccines and Antimicrobials, 3, 22-28. 
immune stress. When the tissues of animal body are invaded by pathogens, naturally or artificially, it can cause immune stress. Immune stress can cause decline of poultry feed intake, weight gain and lean meat deposition and lead to secrete epinephrine and activate hypothalamus-pituitary-adrenal (HPA) axis, these, in turn, increase the circulating glucocorticoid levels [2]. Reported responses to immune stress also include: reduced antibody response and damaged immune organ [3]-[5]. The mechanisms involved in immune stress include organ-, celland molecular-level alterations of the nervous, endocrine, immune systems. All these reports suggest that immune stress could be immunosuppressive for animals. In the first of our immune stress studies, we reported that immune stress was associated with high production of Glucocorticoids, low levels of IgG and pathological tissue changes of immune organ [6] [7]. But the study only shows the changes of the humoral immune function. As in chickens, T cell-mediated immunity plays a crucial role in vaccine-induced protective immunity. The continuous output of naive $\mathrm{T}$ cells from the thymus allows for the increased ability of the host to respond to neo-antigens. So the thymus microenvironment is an excellent example of immune stress. The purpose of the present investigation was to examine its complex relationship with immune stress.

\section{Materials and Methods}

\subsection{Chickens}

Mixed sex, White Leghorn chickens were obtained from the chicken farm of ShanXi Agricultural University. All chickens were maintained in brooder cages with feed and water ad libitum. The chickens were randomly divided into control group (C) and treatment groups $\left(T_{1}\right.$ and $\left.T_{2}\right)$. At 15 days-of-age, Chickens in group $(C)$ were vaccinated with Saline. Chickens in group $\left(T_{1}\right)$ were normally vaccinated with the IV live I-type of Newcastle disease vaccine. Chickens in group $\left(T_{2}\right)$ were vaccinated five times live I-type Newcastle disease vaccine. After vaccination, on day $1,3,5,10,15,21$, five of birds from control group and treatment groups $\left(T_{1}\right.$ and $\left.T_{2}\right)$ were caught to further test respectively.

\subsection{Immunohistochemistry}

The presence of $\mathrm{CD}^{+}$, $\mathrm{CD}^{+} \mathrm{T}$ cells was investigated in thymus using the avidin-biotin complex (ABC) method for immunohistochemistry [8]. The sections were counter-stained with Mayer's haematoxylin and mounted with aqueous mounting medium. The staining intensities observed microscopically were divided into four grades: (negative $=$ no positive cells), + (weak $=$ small number of positive cells per high power field [HPF, approx. $400 \times]),++($ moderate $=$ moderate number of positive cells per HPF), $+++($ strong $=$ accentuated staining pattern with large numbers of positive cells per HPF). In each tissue 10 randomly selected areas of each compartment were evaluated at high power by light microscopy. The judgments were made by calculating percentage of positive $\mathrm{T}$ cells accounted for $100 \mathrm{~T}$ cells.

\subsection{Specimen Preparation for Transmission Electron Microscopy}

The chickens were sacrificed by carotid. After the vaccination, at 8:00 am on the $1 \mathrm{~d}, 3 \mathrm{~d}, 5 \mathrm{~d}, 10 \mathrm{~d}, 15 \mathrm{~d}, 21 \mathrm{~d}$, five chickens from every group were killed. Approximately $1-2 \mathrm{~mm}^{2}$ segments of thymus were extracted with cyclohexane-ethanol and embedded in Spurr's epoxy resin. Sixty-ninety nanometers thick sections were cut with a diamond knife on a Reichert ultramicrotome and stained for 10 min with $1 \% \mathrm{KMnO}_{4}$. Photographs were taken using a Zeiss 10C TEM operated at $80 \mathrm{kV}$ and a Philips CM20 with FEG operating at $160 \mathrm{kV}$ (resolution 0.1 $\mathrm{nm})$.

\section{Results}

\subsection{The Dynamic Changes of CD4+T Cells}

There were many positive $\mathrm{CD} 4^{+} \mathrm{T}$ cells in the cortex and medulla of thymus, especially in the medulla. On third day after vaccination, the numbers of $\mathrm{CD} 4^{+} \mathrm{T}$ cells began to decline in groups (T1 and $\mathrm{T} 2$ ) compared with group (C). The numbers of $\mathrm{CD}^{+} \mathrm{T}$ cells in groups (T1 and T2) were significantly lower than them in group (C) on fifth day $(\mathrm{P}<0.05)$. There was no difference in the number of $\mathrm{CD} 4^{+} \mathrm{T}$ cells between groups (T2) and group (C) on other days. But On fifteen day after vaccination, the numbers of $\mathrm{CD}^{+} \mathrm{T}$ cells began to rise, the numbers of $\mathrm{CD} 4^{+} \mathrm{T}$ cells in groups $(\mathrm{T} 1)$ were significantly higher than them in group $(\mathrm{C})(\mathrm{P}<0.05)$. 


\subsection{The Dynamic Changes of CD8+T Cells}

There were many positive $\mathrm{CD}^{+} \mathrm{T}$ cells in the cortex and medulla of thymus, especially in the medulla. On third day after vaccination, the numbers of $\mathrm{CD}^{+} \mathrm{T}$ cells began to rise in groups (T1 and T2) compared with group (C). The numbers of $\mathrm{CD}^{+} \mathrm{T}$ cells in groups (T2) were significantly higher than them in group(C) on fifth day (P < 0.05). On tenth day after vaccination, the numbers of $\mathrm{CD}^{+} \mathrm{T}$ cells began to decline, but the numbers of $\mathrm{CD}{ }^{+} \mathrm{T}$ cells in groups (T2) were significantly higher than them in control group on fifteen day $(\mathrm{P}<0.05)$.

\subsection{Ultra-Structure of T Cells in Thymus}

The heterochromatin of normal T cells nucleus distributed uniformly. There were more ribosomal particles in the cytoplasm (Figure 1). On first day after vaccination, compared with group $(\mathrm{C})$, the basic structure of the thymus began to disorder in the group (T2). There were many lymphoid apoptotic $\mathrm{T}$ cells and a few necrotic $\mathrm{T}$ cells. The characteristics of apoptotic T cells included cell irregular, nuclear condensation, irregular shape, reduced the ratio of nuclear and cytoplasm. Many vacuoles occupied the cell. The nuclear chromatin concentrated to crescent or massive body (Figure 2). The characteristics of necrotic cells included nuclear concentration, cell swelling, membrane rupturing, cytoplasm spillover (Figure 3). On third day after vaccination, the basic structure of the thymus had been damaged. The number of necrotic $\mathrm{T}$ cells increased. $\mathrm{T}$ cells showed nuclear condensation, cytoplasm out flowing, adjacent cell boundaries being unclear (Figure 4). The nuclear chromatin concentrated to crescent body. The budding membrane formed the apoptotic bodies (Figure 5). Nuclear chromatin gathered the massive body, Many vacuoles occupied the cytoplasm of cell (Figure 6). On fifth day after vaccination, the characteristics of $\mathrm{T}$ cells included nuclear condensation, mitochondrial vacuolar degeneration cytoplasm out flowing, cell lysis. The characteristics of apoptotic T cells appeared (Figures 7-9). On tenth day after vaccination, the necrotic $\mathrm{T}$ cells could not be observed.

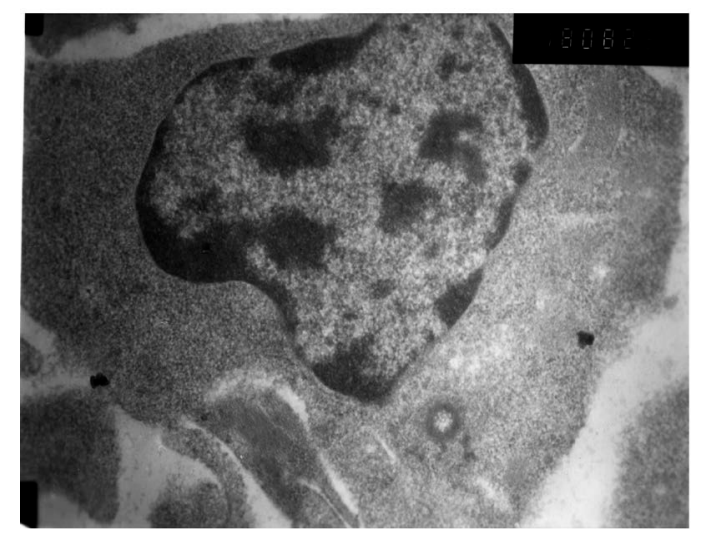

Figure 1. Normal ultra-structure T cells.

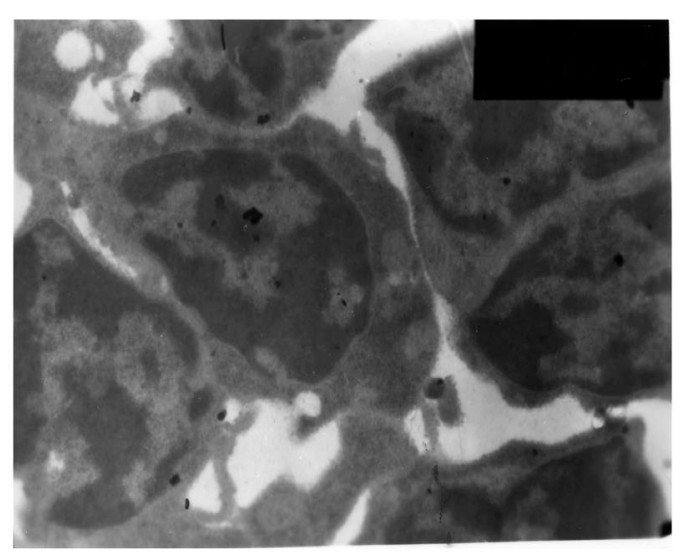

Figure 2. The first day after vaccination. 


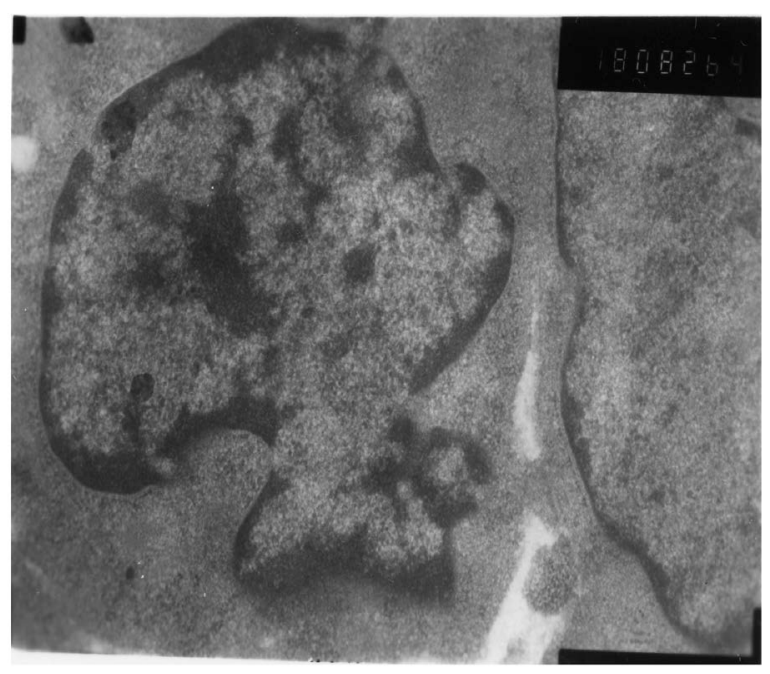

Figure 3. The first day after vaccination.

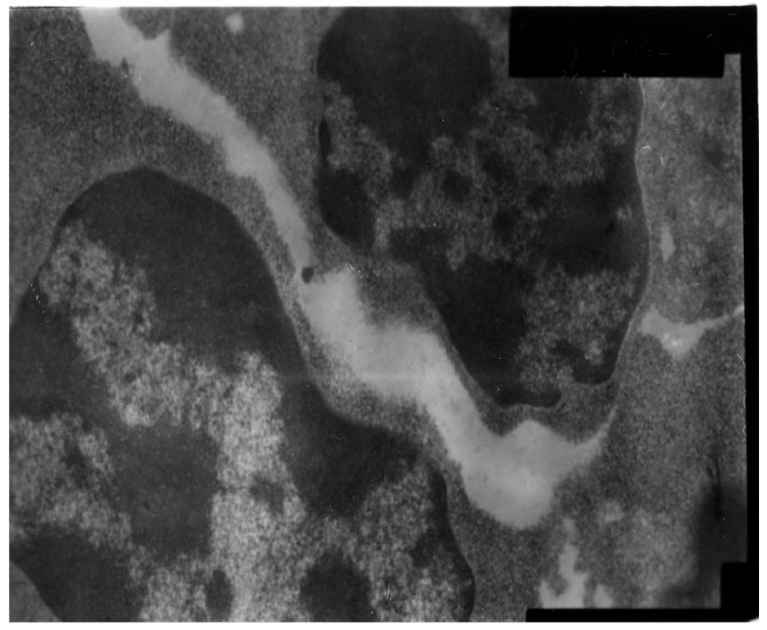

Figure 4. The third day after vaccination.

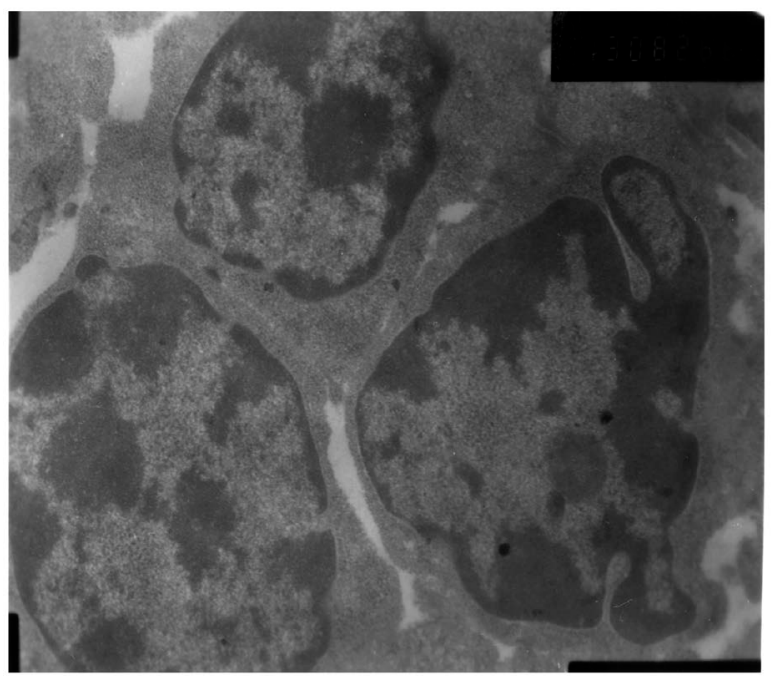

Figure 5. The third day after vaccination. 


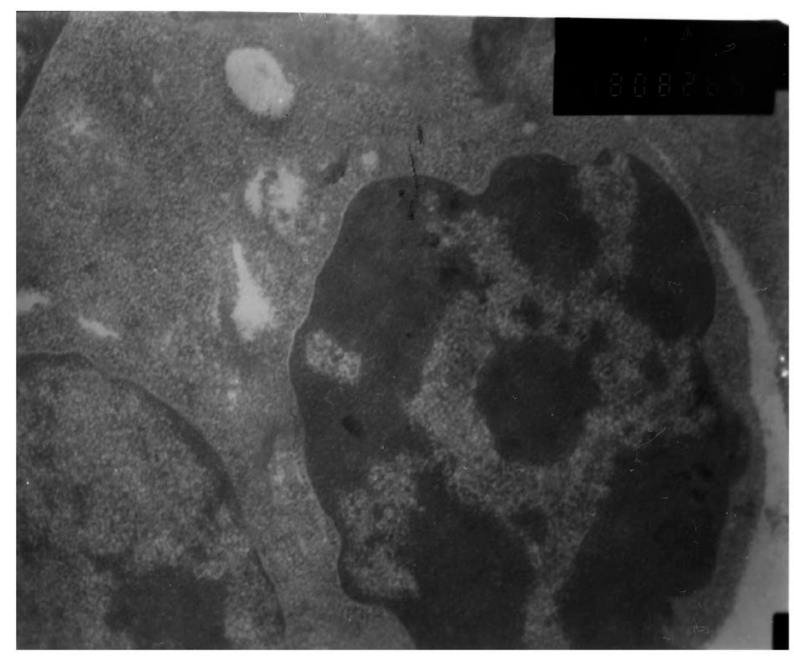

Figure 6. The third day after vaccination.

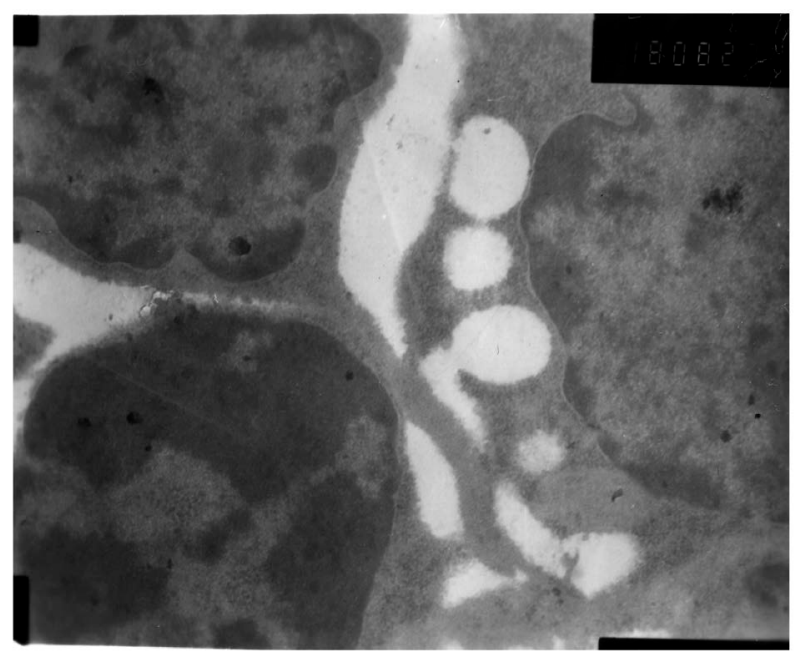

Figure 7. The fifth day after vaccination.

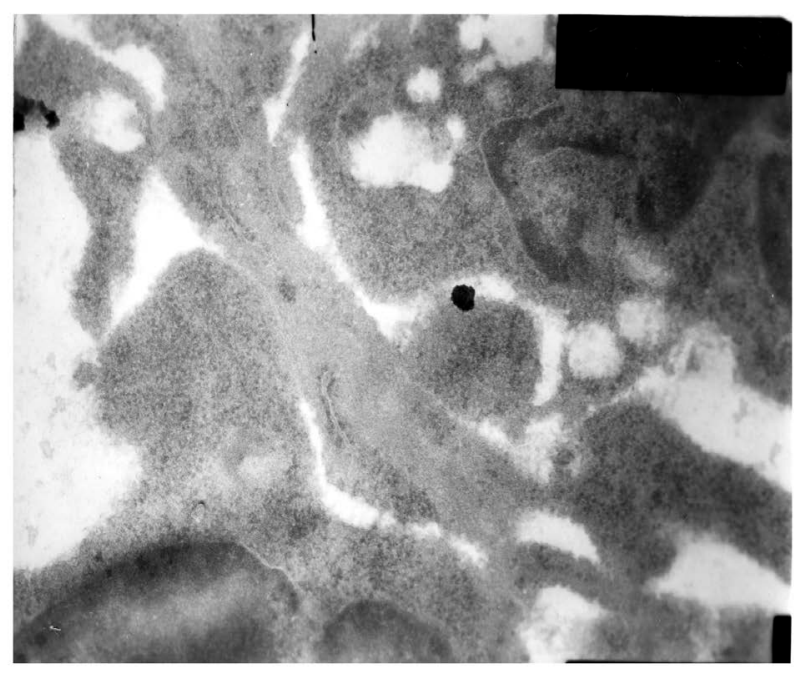

Figure 8. The fifth day after vaccination. 


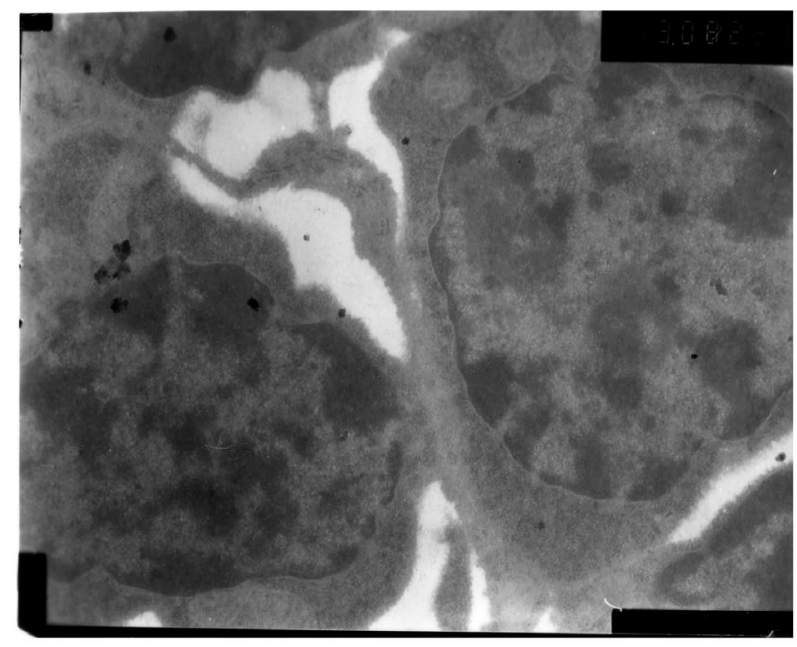

Figure 9. The fifth day after vaccination.

\section{Discussion}

Whether vaccination will trigger immune stress appears to depend on several factors, including the vaccine of the challenge to the immune system, acupuncture, capture, because the live I-type of Newcastle disease vaccine has moderate virulence, adding the role of acupuncture and capture the chicks. These are strong stresses for chicken [9]. Our preliminary studies also showed that the model of experimental immune stress could be built by overdose of live I-type Newcastle disease vaccine [10].

Thymocyte developmental stages can readily be defined by the expression of the cell surface receptors CD4+ and $\mathrm{CD}^{+}$. $\mathrm{CD}^{+}$and $\mathrm{CD}^{+} \mathrm{T}$ cells maintain a state of equilibrium, as the foreign antigen stimulation [11]. According to the characteristics of T cells, they fall into two categories. One is defined as T-helper cells (TH) and suppressor T cells (TS). The other is defined as cytotoxic lymphocyte (CTL) and delayed type hypersensitivity (TDTH). TH cells and TS cells belong to the $\mathrm{CD} 4^{+}$and $\mathrm{CD} 8^{+} \mathrm{T}$ cells respectively. TH cells can stimulate B cells to proliferate and produce antibodies, and also participate in cell-mediated immunity. TS cells can inhibit the activation of the immune response. TS cells play an important role in the regulation of immune cells. The main targets of TS cells are TH cells and B cells [12]. CTL is the inactive precursor forms of CD8 ${ }^{+} \mathrm{T}$ cells. Our preliminary studies showed the titer of ND antibody and IgG in Serum tended to decline after immune stress. These studies showed that the numbers of $\mathrm{CD}^{+} \mathrm{T}$ cells in groups (T1 and $\mathrm{T} 2$ ) were significantly higher than those in group (C) on fifth day. Thus, according to these results, CD8 ${ }^{+} \mathrm{T}$ cells may inhibit the part activation of TH cells and $\mathrm{B}$ cells. The number changes for $\mathrm{CD} 8^{+} \mathrm{T}$ cells could be the self-protection mechanism of immune system to face plenty of viruses.

The immune system should not be viewed as an autonomous entity, but rather as one component of an interactive network constituted by the immune, nervous, and endocrine systems. Various studies have focused on the relationships between GC and the development of T cells in the thymus. Due to an increase of GC, for the thymus, the observed involution could be associated with an increase of thymocyte apoptosis. To avoid the disorder of immune system, many $\mathrm{T}$ cells were induced apoptosis after immune stress. It may help immune response to clear the excess activated $\mathrm{T}$ cells thereby and maintain stability of immune response. At the same time, the immune stress caused the pathological changes of T cells [13]. On the tenth day after vaccination, the pathological $\mathrm{T}$ cells could not be observed. The result showed that immune stress, as an acute stress, could cause the damage to the body. But the damage was temporary, it may be restored by regulating its own immune system.

It has been suggested that immune stress is immunosuppressive. Dhabhar and McEwen have argued that immunoenhancement by acute stress would be adaptive from an evolutionary stand point, and might be regarded as an integral component of the fight or flight response [14]. From this perspective, circumstances that initiate a fight or flight response are also likely to involve exposure in antigens and, therefore, a robust immune response would be adaptive for survival. Our results underscore: the immune stress could cause transient immunosuppresstion. The reasons in this study are as follows: (1) $\mathrm{CD}^{+} \mathrm{T}$ cells may inhibit part of the activation of $\mathrm{TH}$ cells and $\mathrm{B}$ cells and the changes for $\mathrm{CD}^{+} \mathrm{T}$ cells could be faced plenty of viruses. (2) part of T cells of chicken thy- 
mus came with apoptotic and pathological changes of putrescence continually. But, the aim of these changes for chickens was the self-protection mechanism of immune system to avoid immune disorder and adapt to survival.

\section{Acknowledgements}

The study was supported by the Soft Science Foundation of Shanxi Province (2013041038-02) and Natural Science Foundation of Shanxi Normal University (ZK1301, YK1301). It was also supported by the Students Innovation Foundation of Shanxi Normal University (SD2013CXCY-82).

\section{References}

[1] Dalgaard, T.S., et al. (2010) Flow Cytometric Assessment of Chicken T Cell-Mediated Immune Responses after Newcastle Disease Virus Vaccination and Challenge. Vaccine, 28, 4506-4514. http://dx.doi.org/10.1016/j.vaccine.2010.04.044

[2] Dominguez-Gerpe, L. and Rey-Mendez, M. (2000) Role of Pre-T Cells and Chemoattractants on Stress-Associated Thymus Involution. Scandinavian Journal of Immunology, 52, 470-476.

[3] Mast, J., et al. (2006) Vaccination of Chicken Embryos with Escape Mutants of La Sota Newcastle Disease Virus Induces a Protective Immune Response. Vaccine, 24, 1756-1765. http://dx.doi.org/10.1016/j.vaccine.2005.10.020

[4] Knueppel, D., et al. (2010) Impact of Vaccination against Chicken Newcastle Disease on Food Intake and Food Security in Rural Households in Tanzania. Food and Nutrition Bulletin, 1, 31, 436-445.

[5] Mansoori, B. and Modirsanei, M. (2012) Effects of Dietary Tannic Acid and Vaccination on the Course of Coccidiosis in Experimentally Challenged Broiler Chicken. Veterinary Parasitology, 187, 119-122. http://dx.doi.org/10.1016/j.vetpar.2011.12.016

[6] Gao, W.W and Ren, J.Y. (2001) The Influence of Experimental Immunological Stress on Immunological Function of Chicken. Journal of Shanxi Agricultural Sciences, 29, 80-84.

[7] Tian, W.X. (2000) Effect of Dynamic Changes of Antibody Producing Cells of Immune Organs and Tissues of Experemental Immunologic Stress Chickens. Journal of Shanxi Agricultural University, 3, 232-235.

[8] Cattoretti, G., et al. (1988) Improved Avidin-Biotin-Peroxidase Complex (ABC) Staining. Histochemical Journal, 20, 75-80. http://dx.doi.org/10.1007/BF01746607

[9] Henning, J., et al. (2009) Evaluation of Strategies to Improve Village Chicken Production: Controlled Field Trials to Assess Effects of Newcastle Disease Vaccination and Altered Chick Rearing in Myanmar [Corrected]. Preventive Veterinary Medicine, 90, 17-30. http://dx.doi.org/10.1016/j.prevetmed.2009.04.007

[10] Xu, T., Gao, W. and Ren, J.Y. (2002) Effects of Experimental Immunologic Stress on Blood Hormone and Immunity in Chickens. Acta Agriculturae Boreali-Sinica, 17, 114-118.

[11] Lv, Q., Zhang, S. and Zhao, R. (2008) Transportation Stress Alters the Expression of Immunoregulatory Cytokines in the Porcine Thymus. The Veterinary Journal, 187, 229-233. http://dx.doi.org/10.1016/j.tvjl.2009.12.004

[12] Frazer, I.H. and Mackay, I.R. (1985) A Graphical Presentation of Counts of T Lymphocyte Subpopulations and Th-Ts Ratios. Pathology, 17, 62-63. http://dx.doi.org/10.3109/00313028509063726

[13] Franchini, A., Marchesini, E. and Ottaviani, E. (2004) Corticosterone 21-Acetate in Vivo Induces Acute Stress in Chicken Thymus: Cell Proliferation, Apoptosis and Cytokine Responses. Histology and Histopathology, 19, 693-699.

[14] Dhabhar, F.S. and McEwen, B.S. (1999) Enhancing versus Suppressive Effects of Stress Hormones on Skin Immune Function. Proceedings of the National Academy of Sciences of the USA, 96, 1059-1064. http://dx.doi.org/10.1073/pnas.96.3.1059 